\title{
SAND STABILIZATION BY USING UREA-FORMALDEHYDE RESIN
}

\author{
تثبيت الرمل باستخدام راتتج اليوريا فورمالدهايد \\ ISLAM M. ABO ELNAGA \\ Lecturer, Civil Engineering Department \\ Higher Institute of Engineering and Technology-Kafr El-Sheikh \\ Kafr El-Sheikh, EGYPT
}

\begin{abstract}
This paper presents the results of detailed laboratory tests to improve the natural subgrade soils using polymer resins. The improvement may be through increasing compressive strength, flexural strength and California bearing ratio. The urea-formaldehyde resin was used in this study, as a soil stabilizing agent, to improve the characteristics of desert and beach sands. Comparison was done of properties of soil with no modified urea-formaldehyde resin with the properties of soil with modified urea-formaldehyde resin. The results are encouraging since the addition of the ureaformaldehyde resin increase the compressive strength which enables the sands to carry the heavy traffic. In addition, California bearing ratio, dry density, abrasion resistance and water absorption have been improved to use in the construction of highways.
\end{abstract}

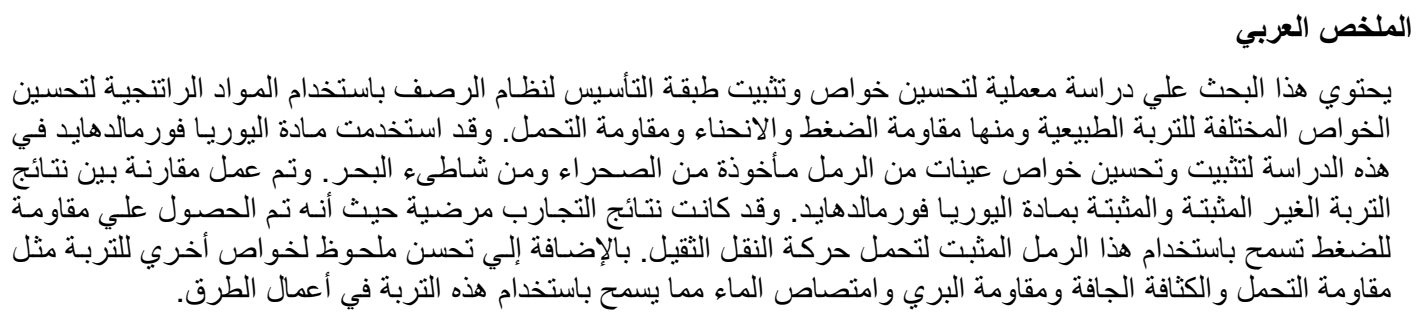

KEYWORDS: Stabilization, Polymerization, Urea-Formaldehyde Resin and curing time.

\section{INTRODUCTION}

Highway engineers are interested in the basic engineering properties of soils because soils are used extensively in highway construction. Soil properties are of significant importance when a highway is to carry high traffic volumes with a large percentage of trucks [1]. They are also of importance when high embankments are to be constructed and when the soil to be strengthened and used as intermediate support for the highway pavement [2]. In a flexible pavement, the bituminous concrete and it's under courses distribute loads downwards to the subgrade soil. Additional strength in the subgrade soil can lead to a prolonged pavement lifetime. Recently many investigations are done to study the possibility of using polymers to modify the properties of some types of soil. Polymeric materials possess outstanding tensile strength, chemical inertness, good adhesion to other materials and other valuable properties which draw considerable attention for their use in soil stabilization.

The urea-formaldehyde resin was used to stabilization of brown shale gravel. The results 
indicated that, addition of $2 \%$ of urea-formaldehyde resin was sufficient to raise the indirect tensile strength in dry case to $340 \mathrm{KPa}$ but the strength in wet case was still poor [3]. Stabilization of fine sand is the longest-established and most widely used grouting technique. It involves the filling of the pore space of soils. The objective is to fill a void space without displacement of the formation or any change in the void configuration or volume [4]. Fine alluvial sand stabilized with multi-molecular organic solutions. Comparison was done of properties of conventional multi-molecular organic solutions on basis of urea-formaldehyde resins with properties of modified with active component solutions. Compressed strength of sands stabilized with multimolecular organic solutions is time dependent and increased from 2.2 $\mathrm{MPa}$ after 7 days to $2.9 \mathrm{MPa}$ after 3 months. 12 to 19 times less formaldehyde is liberated into the air from soil stabilized with the modified solutions than from the soil stabilized with the conventional solutions [5].

Permeable soils strengthened were studied with modified polymer resins in laboratory and field over a period of one year. Comparison was done of properties of no modified urea formaldehyde resins with properties of modified urea-formaldehyde resins. Results of field tests confirmed the results of The goal of this study is centered on the possibility of using the available local urea-formaldehyde resins to stabilize different types of sands: desert sand, uncleaned beach sand and washed beach sand. The investigation includes the effect of use of the ureaformaldehyde resins on sand properties such as compressive strength, flexural strength, California bearing ratio, dry density water absorption and abrasion resistance. Also, the investigation includes the effect of the time of air curing on the above properties.

\section{THE MECHANISM OF POLYMERIZATION}

Polymer are macro molecules built up by the linking together of large numbers of much smaller molecules. The small molecules which combine with each other to form polymer molecules are termed "monomers". The reaction by which they combine is termed "polymerization". Polymers are classified as linear, branched or cross linked polymers depending on the structure shape of the polymer molecules. Urea-formaldehyde resin has an excessive rigidity due to extensive cross-linking which leads to an inability to crystallize. Urea-formaldehyde resin shows the characteristics of highly viscous liquids. The polymerization of urea-formaldehyde resin under mildly basic conditions yields methyl derivatives such as mono- methlolurea $\left(\mathrm{HOCH}_{2}-\mathrm{NH}-\mathrm{CO}-\mathrm{NH}_{2}\right)$ and di-methlolurea $\left(\mathrm{HOCH}_{2}-\mathrm{NH}-\mathrm{CO}-\mathrm{NH}-\mathrm{CH}_{2} \mathrm{OH}\right)$ which are then polymerized to network structures under neutral or slightly acid conditions [10]. The laboratory tests. Addition of active components to urea-formaldehyde resins increase density and $\mathrm{pH}$ of solution of urea-formaldehyde resin, decrease viscosity. Uniaxial strength of sands stabilized with polymer resins is highly time dependent [1]. The use of urea-formaldehyde resin is used in stabilized of some types of soils. The properties of soil samples with of urea-formaldehyde resin were determined. Several samples of soil and resin mixed in different ratios were prepared. The results show that the addition of the of urea-formaldehyde resin increase the compressibility module, the load strength and the bearing capacity of the stabilized soil. Also, the structures erected on the soils stabilized by of ureaformaldehyde resin may be expected to settle less [6]. Sand of Maadi-desert near Cairo has been stabilized using polmeric materials which resulted in improvement of its absorption and strength properties [7]. A number of polymeric materials were used in the Soviet Union as "structure forming agents" suitable for creating highly water resistant and mechanically strong soil structures to control erosion by wind and water on farm lands under cultivation [8]. Japanese used polymeric materials in road construction and bridge deck overlays for the negligible permeability and high strength of the mixture [9].

nature of the cross linking reaction is out of scope of this paper.

\section{USED MATERIALS AND TESTING PROGRAM}

The chemical composition of sand determines the type of polymer to be used. The urea-formaldehyde resin is the beat type of resins to be used for sand stabilization due to sand contains a high percent of Silicon Oxide $\mathrm{Sio}_{2}$.

\subsection{Sand Samples}

Three different types of sand samples were used. They are:

Sand I: Obtained from a depth of one meter below the ground surface from Cairo-Alexandria desert road around the El-Aameria city.

Sand II: Obtained from Balteem beach to represent beach sand with salts and chlorides.

Sand III: Obtained from Balteem beach to after washing with tap water.

The chemical analysis of the three types of sand is given in Table (1) and (2).

\subsection{Urea-Formaldehyde Resin}

Urea-formaldehyde resin is classified as a thermo set material. The high degree of cross linking is used to import high rigidity and dimensional stability under conditions of heat and stress. Most mechanical properties depend on and vary considerably with molecular weight. The urea-formaldehyde polymer is generally characterized by; the high rigidity and high 
resistance to deformation, the modulus of elasticity ranges from $6.895 \times 10^{5}$ to $3.448 \times 10^{6} \mathrm{kN} / \mathrm{m}^{2}$ and the tensile strength is 34475 to $82740 \mathrm{KN} / \mathrm{m}^{2}$. Also, it has a very small elongation ( 0.5 to $3.0 \%)$.

The amorphous polymer with high chain rigidity is achieved by extensive cross linking. It can bond and link sand mineral particles and becomes insoluble after the reaction is completed and it resists the biochemical decomposition. The sample of the ureaformaldehyde resin used in this work is produced by "Mansoura for Resins and Chemical Industries Company" at El-Mansoura [11]. The specifications of the used urea-formaldehyde resin are given in Table (3).

\subsection{Testing Program}

The selected three types of sand mixed with ureaformaldehyde resin percentage of $4 \%, 5 \%, 6 \%, 7 \%$ and $8 \%$ by weight. The time of air curing of mixtures was divided into 7, 14, 21 and 28 days after preparation. Soaking of specimens in water where samples were allowed to soak in water for one day before performing tests. In addition ammonium chloride was used to accelerate polymerization process. For each specimen, the following properties were determined; compressive strength, flexural strength, California bearing ratio, the maximum dry density, abrasion resistance and water absorption.

\section{ANALYSIS AND DISCUSSION OF RESULTS}

\subsection{The Compressive Strength}

Figure (1) Relationship between compressive strength at 28-days and the percentage of ureaformaldehyde (by weight) for all types of sands. From this Figure, it could be seen that, the value of compressive strength of desert sand was increased with the percentage of the added urea-formaldehyde resin increases with a peaking value showing an optimum at $5.8 \%$ then it starts to decrease. For beach sand either before or after washing, the compressive strength increases steadily to the maximum percentage of added urea-formaldehyde resin $8 \%$. Also, it could be found that, the compressive strength increase with increasing air curing time. From Figure (1), it could be concluded that, the maximum obtained values of compressive strength after 28 days for desert sans, beach sand and washed beach sand were 90, 143 and $159 \mathrm{~kg} / \mathrm{cm}^{2}$, respectively. These values are quite suitable for many structural and highways construction uses. Soaking the ureaformaldehyde treated specimens in water for 24hours after 28-days air curing time reduces the compressive strength to about $40 \%$ of the original value before soaking. This may be due to the long curing time required to complete the polymerization process before soaking.

\subsection{Flexural Strength}

Summary of test results are given in Figure (2). It could be seen that, increasing the percentage of added urea-formaldehyde resin resulted in an increase in flexural strength. This increase peaked at $5.8 \%$ for desert sand, while it was steady for beach sand before or after washing with water. The maximum achieved values of the modulus of rupture for the desert sand, beach sand and washed sand were 47,50 and $54 \mathrm{~kg} / \mathrm{cm}^{2}$, respectively. Soaking the ureaformaldehyde treated specimens in water for 24hours after 28-days air curing time reduces the flexural strength to about $40-50 \%$ due to the incompleteness of the polymerization process.

\subsection{Abrasion Resistance}

Summary of test results are given in Figure (3). From this Figure, it could be found that, the percentage of losses in weight by abrasion decreases with increasing air curing and by adding ureaformaldehyde resin up to $6.7 \%$ for desert sand. $6 \%$ for beach sand and $8 \%$ for washed sand. After these percentages, the losses reach approximately a steady state giving percentages of wear between 4 to $5.5 \%$ by weight for all specimens. The maximum values of abrasion losses for treated samples ranged from 4 to $5 \%$ by weight after 28 -days air curing time.

\subsection{Water Absorption}

Figure (4) shows the relationship between water absorption at 28 days and the percentage of ureaformaldehyde resin for all types of Sands. From this Figure, it could be found that, the percentage of water absorption decreases with increasing the percentage of urea-formaldehyde resin up to $6.5 \%$ for desert and beach sands, while it reaches $8 \%$ for washed beach sand. Also, it could be seen that, the percentage of water absorption decreases with increasing the air curing time. The minimum value of the percentage of water absorbed of all types of sands is about $6.5 \%$ of urea-formaldehyde resin. This value was obtained after 28-days air curing time.

\subsection{California Bearing Ratio (CBR)}

Figure (5) shows the relationship between Califorina bearing ratio (CBR \%) at 28-days and the percentage of urea-formaldehyde resin (by weight) for all types of sands. From this Figure, it could be seen that, the value of Califorina bearing ratio CBR of desert and beach sands were increased with the percentage of the added urea-formaldehyde resin increases with a peaking value showing an optimum at $6.1 \%$ then it starts to decrease. Also, it could be found that, the Califorina bearing ratio $\mathrm{CBR}$ increases with increasing air curing time. From Figure (5), it could be concluded that, the maximum obtained values of Califorina bearing ratio CBR after 28-days for desert sand, beach sand and washed beach sand were 11, 11.2 and $11.3 \%$, respectively. 


\subsection{Maximum Dry Density}

Figure (6) shows the relationship between maximum dry density at 28-days and the percentage of ureaformaldehyde resin (by weight) for all types of sands. From this Figure, it could be seen that, the value of the maximum dry density of desert and beach sands were increased with the percentage of the added urea-formaldehyde resin increases with a peaking value showing an optimum at $5.4 \%$ then it starts to decrease. Also, it could be found that, the maximum dry density increases with increasing air curing time. From Figure (6), it could be concluded that, the maximum obtained values of maximum dry density after 28-days for desert sand, beach sand and washed beach sand were $1.99,2.01$ and $1.97 \mathrm{gm} / \mathrm{cm}^{3}$, respectively.

\section{CONCLUSIONS}

Based on the test result and above analysis, the following conclusions of this study are summarized below.

1. Adding $5.8 \%$ of urea-formaldehyde resin to medium size desert sand gives about $90 \mathrm{Kg} / \mathrm{cm}^{2}$ compressive strength after 28 days curing time. The same amount enables the beach fine sand to withstand $130 \mathrm{Kg} / \mathrm{cm}^{2}$ compressive strength curing time. This means that urea-formaldehyde resin treated sands will satisfy the AASHTO requirements with higher factor of safety for all types of tested fine and medium sands.

2. The compressive strength of sands treated with urea-formaldehyde resin increases with the increase of curing time in air.

3. Washing the beach sand with tap water increases the $\mathrm{P}^{\mathrm{H}}$ value. This gives the higher compressive and flexural strengths values.

4. Abrasion losses reach a minimum value $(3 \%)$ by adding (5.8-6\%) urea-formaldehyde resin to sand by weight for all types of sands. The abrasion losses may be decreased also by increasing air curing time. The same percent of urea-formaldehyde resin may decrease the ability of specimens for water absorption to its minimum value (6\%).

5. The value of Califorina bearing ratio CBR of desert and beach sands were increased with the percentage of the added urea-formaldehyde resin increases with a peaking value showing an optimum at $6.1 \%$ then it starts to decrease. Also, it could be found that, the Califorina bearing ratio CBR increases with increasing air curing time.

6. The maximum dry density of desert and beach sands were increased with the percentage of the added urea-formaldehyde resin increases with a peaking value showing an optimum at $5.4 \%$ then it starts to decrease. Also, it could be found that, the maximum dry density increases with increasing air curing time

\section{REFERENCES}

[1] Mackevicius R.: "Strengthening of Permeable Soils by Grouting with Modified Polymer Resins" The $8^{\text {th }}$ International Conference of Environmental Engineering, Volume I, p.p. 1128-1132, Vilnius Gediminas Technical University, Lithuania, (2011).

[2] Garber N. J. and Hoel L. A.: "Traffic and Highway Engineering", $4^{\text {th }}$ ed. Cengage Learning, Toronto, page 1230, ISBN 9780495082507, (2009).

[3] Germishuizen W. A., Focke W. W. and Visser A. T.: "A Laboratory Study of Soil Stabilization with a Urea-Formaldehyde Resin", Jornal of the South African Institution of Civil Engineering, 44 (1), p. p. 9-12, (2002).

[4] Warner, J.: "Practical Handbook of Grouting- Soil, Rock and Structures" John Wiley and Sons, 700 P, ISNB 0471463035, (2004)

[5] Mackevicius R.: "Stabilization of Fine Alluvial Sand with Multi-Molecular Organic Solution" The $10^{\text {th }}$ International Conference of Modern Building Materials, Structures and Techniques, Vilnius Gedimins Technical University, Lithuania, (2010).

[6] Levacic, E. and Baravar, M.: "Soil Stabilization by Means of UreaFormaldehyde Resin" Geoloski-Naftni Zbornik, Volume 2, Zagreb, (1990).

[7] El-Demery, M. G.: "Stabilization of Foundation Bed Using UreaFormaldehyde Resin and Araldite Resins" Journal of Egyptian Society of Engineers, Volume XVII, No 1, (1978).

[8] Revut, I. B.: "Increasing the Fertility and Resistance to Erosion of Soil" Soviet Plastics, N0 10, (1972).

[9] Lizzo, M. A.: "Status of Concrete Polymer Composite in U. S. and Abroad" Public Road Journal of Highway Research and Development, Volume 37, No 4, p.p. 129135, (1973).

[10] Odian, G.: " Principles of Polymerization" McGraw Hill Company, (1975).

[11] Mansoura for Resins and Chemical Industries Company S. A. E., ElMansoura, Egypt, (2013). 
Table (1): Chemical Analysis of the Three Types of Sands (Soluble Salte Content)

\begin{tabular}{|c|c|c|c|}
\hline Salt & Sand I & Sand II & Sand III \\
\hline Chloride $^{-} \mathrm{Cl}^{-}$ & 0.16 & 0.30 & 0.15 \\
\hline Sulphate $^{--} \mathrm{So}_{3}^{--}$ & 0.10 & 0,20 & 0.10 \\
\hline Sodium $^{+} \mathrm{Na}^{+}$ & 0.00 & 0.05 & 0.00 \\
\hline Potasium $^{+} \mathrm{K}^{+}$ & 0.00 & 0.02 & 0.00 \\
\hline $\mathrm{P}^{\mathrm{H}}$ & 7.2 & 7.80 & 8.00 \\
\hline
\end{tabular}

Table (2): Chemical Analysis of the Three Types of Sands (Oxide Content)

\begin{tabular}{|c|c|c|c|}
\hline Oxide & Sand I & Sand II & Sand III \\
\hline Silicon Oxide $\mathrm{SiO}_{2}$ & 91.7 & 84.28 & 87.80 \\
\hline Aluminium Oxide $\mathrm{Al}_{2} \mathrm{O}_{3}$ & 1.52 & 5.62 & 4.20 \\
\hline Ferric Oxide $\mathrm{Fe}_{2} \mathrm{O}_{3}$ & 1.63 & 1.97 & 1.82 \\
\hline Titanium Oxide $\mathrm{Tio}_{2}$ & 0.33 & 0.42 & 0.22 \\
\hline Calcium Oxide Cao & 1.43 & 2.48 & 1.76 \\
\hline Magnesium Mgo & 0.28 & 0.67 & 0.48 \\
\hline Sodium Oxide $\mathrm{Na}_{2} \mathrm{O}$ & 0.37 & 1.62 & 0.56 \\
\hline Potassium Oxide $\mathrm{E}_{2} \mathrm{O}$ & 0.62 & 1.16 & 1.10 \\
\hline Sulpher Trioxide $\mathrm{So}_{3}$ & 0.57 & 0.58 & 0.56 \\
\hline L.O.I & 1.25 & 1.14 & 1.12 \\
\hline
\end{tabular}


Table (3): Characteristics of Urea-Formaldehyde Resin [11]

\begin{tabular}{|l|l|}
\hline \multicolumn{1}{|c|}{ Character } & \multicolumn{1}{|c|}{ Specifications } \\
\hline Appearance & Milky Liquid free from foreign matter \\
\hline $\mathrm{P}^{\mathrm{H}}$ & $7.8-8.8$ \\
\hline Solid Content $\left(3 \mathrm{~h} / 120^{\circ} \mathrm{C}\right)$ & $(60 \pm 2) \%$ \\
\hline Viscosity @ $20^{\circ} \mathrm{C}$ & $(350-450)$ cps \\
\hline Gel Time @ $100^{\circ} \mathrm{C}$ & $(65-90)$ sec \\
\hline Specific Gravity @ $20{ }^{\circ} \mathrm{C}$ & $(1.25 \pm 0.02)$ \\
\hline Shelf Life @ $25^{\circ} \mathrm{C}$ & One Month \\
\hline Chemical Stability in Water & Stable \\
\hline Storage & In Plastic Containers \\
\hline Handling & It is very sensitive to $\mathrm{P}^{\mathrm{H}}$ and high temperature \\
\hline
\end{tabular}

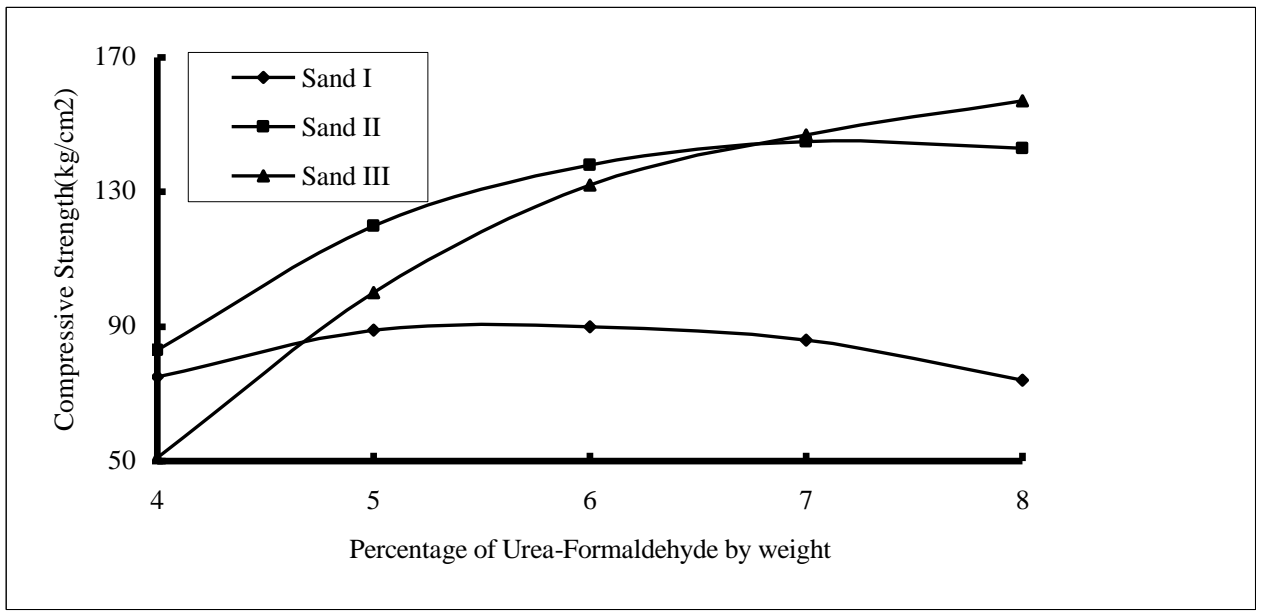

Figure 1: Relationship between Compressive Strength $\left(\mathrm{kg} / \mathrm{cm}^{2}\right)$ at 28 days and the Percentage of Urea-Formaldehyde (by weight) for all types of Sands. 


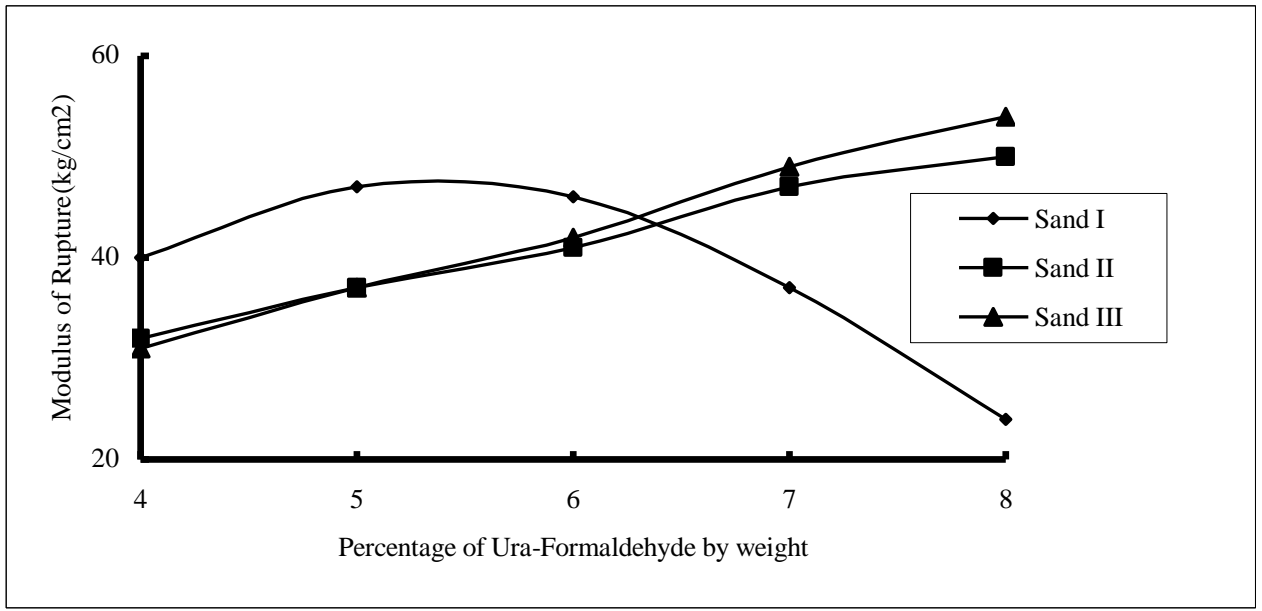

Figure 2: Relationship between Modulus of Rupture $\left(\mathrm{kg} / \mathrm{cm}^{2}\right)$ at 28 days and the Percentage of Urea-Formaldehyde (by weight) for all types of Sands.

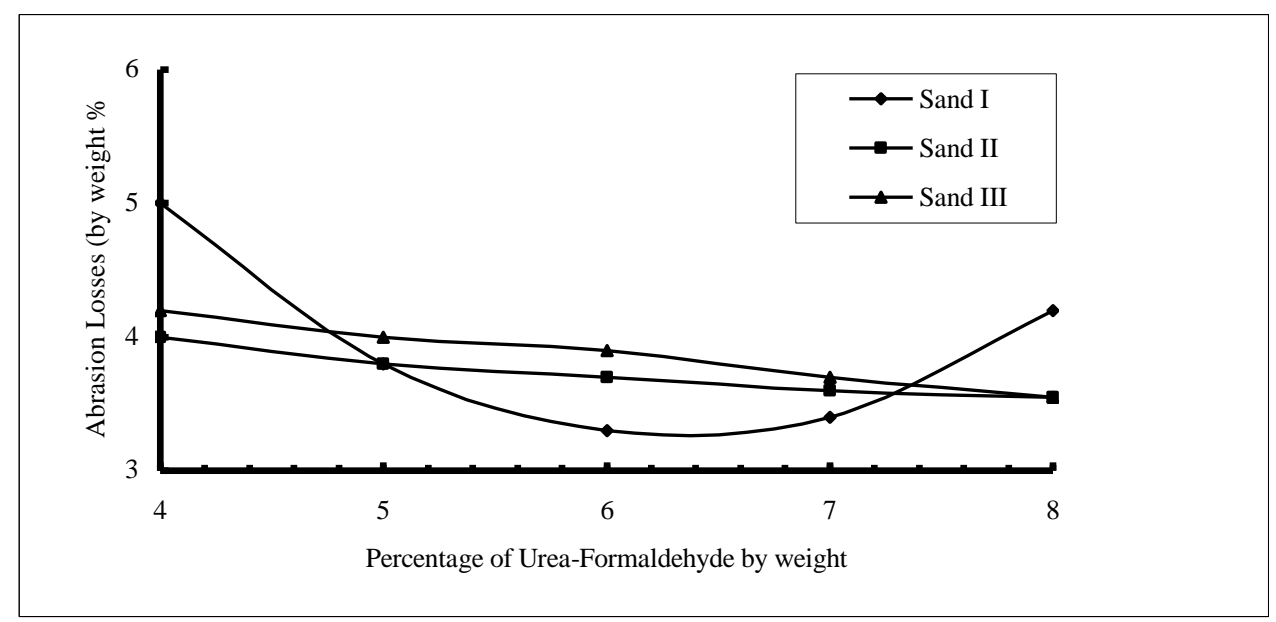

Figure 3: Relationship between Abrasion Losses (by weight \%) at 28 days and the Percentage of Urea-Formaldehyde (by weight) for all types of Sands.

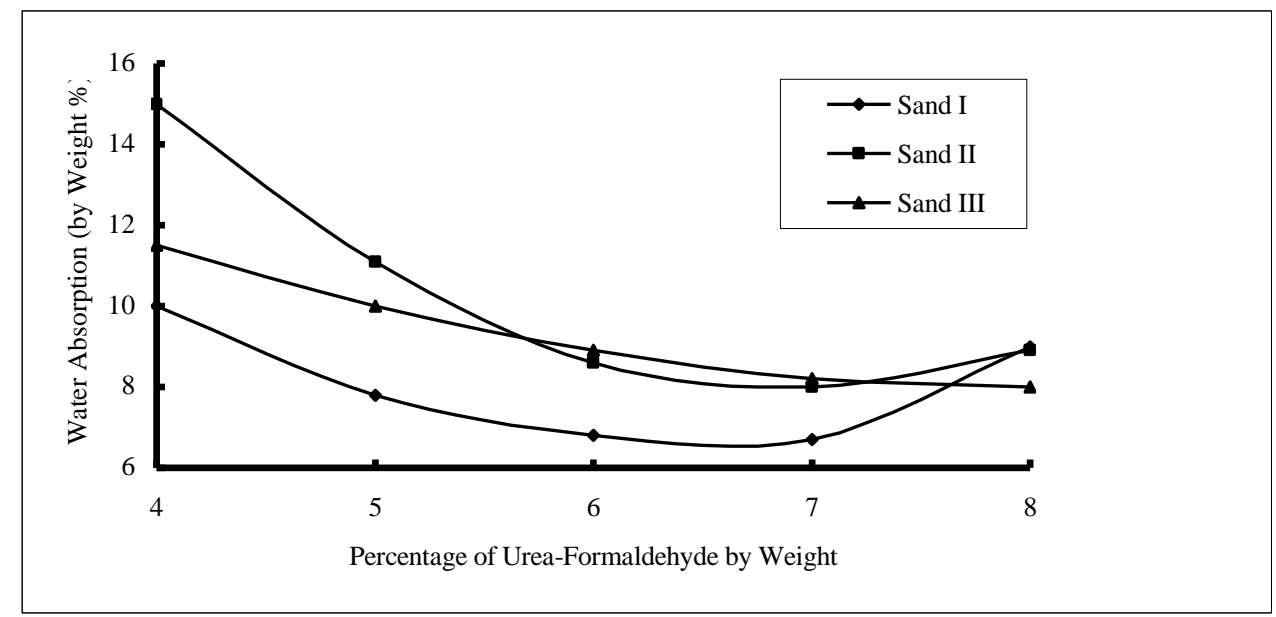

Figure 4: Relationship between Water Absorption (by weight \%) at 28 days and the Percentage of Urea-Formaldehyde (by weight) for all types of Sands. 
Islam m. Abo Elnaga " SAND STABILIZATION BY USING UREA....

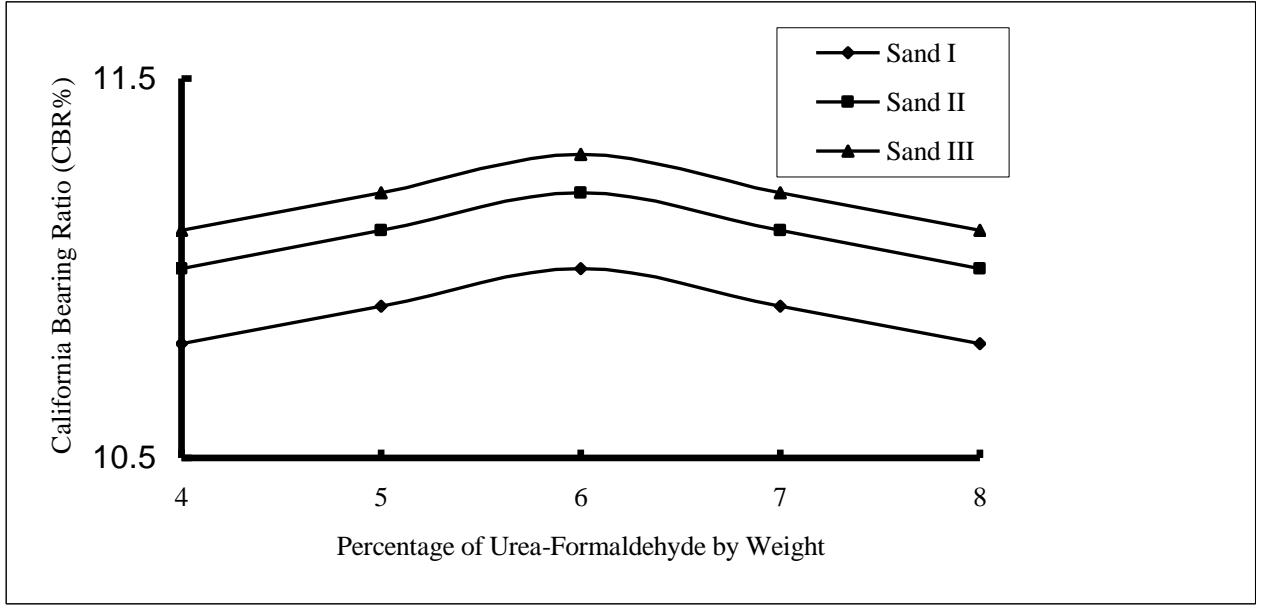

Figure 5: Relationship between Califorina Bearing Ratio (CBR \%) at 28 days and the Percentage of Urea-Formaldehyde (by weight) for all types of Sands.

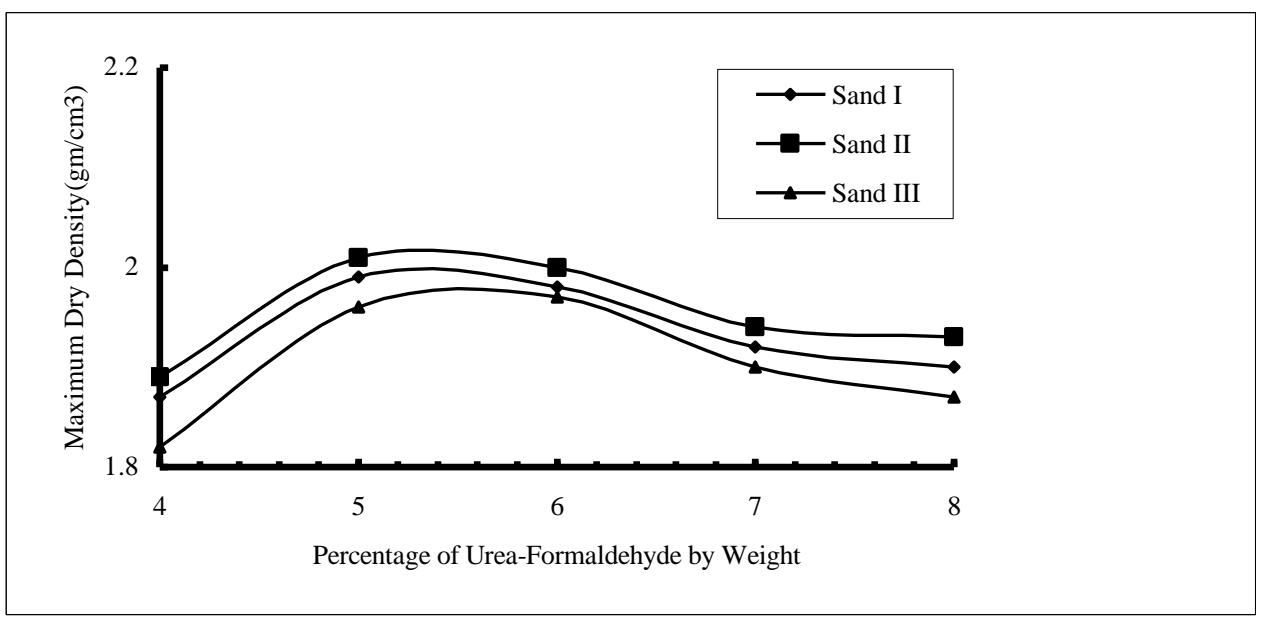

Figure 6: Relationship between Maximum Dry Density at 28 days $\left(\mathrm{gm} / \mathrm{cm}^{3}\right)$ and the Percentage of Urea-Formaldehyde (by weight) for all types of Sands. 